\title{
Resident research: why some do and others don't
}

\author{
Jason Yongsheng $\underline{C h a n}^{1}$, MBBS, MRCP, Kaavya Narasimhalu${ }^{2}$, MRCP, PhD, Orlanda $\underline{G o h}^{2}$, MBBS, MRCP, Xiaohui Xin ${ }^{3}$, MA, \\ Tien Yin Wong ${ }^{4,5}$, FRCS, PhD, Julian $\underline{\text { Thumboo }}^{5,6}$, MBBS, FRCP, Ghee Chee $\underline{\text { Phua }}^{5,7}$, MBBS, MRCP
}

INTRODUCTION Although research is widely considered to be a relevant and essential skill to resident development, the actual participation rate of residents in research remains low, and the factors associated with participation are unclear. METHODS We examined the participation rate of junior residents in research, and their attitudes and perceived barriers toward research, via an anonymised survey carried out from October to November 2013. The residents were from an established Accreditation Council for Graduate Medical Education-accredited internal medicine residency training programme in Singapore.

RESULTS The overall response rate was $64.1 \%$ (82/128 residents). The most frequently cited barrier was lack of time. Only a third of the residents surveyed were actively participating in research. Those with postgraduate qualifications were more likely to be involved in research (odds ratio $4.71, p=0.015$ ). Among the 82 residents, $40.2 \%$ reported an interest in research as part of their career; these were mainly graduates from overseas universities or postgraduates. A belief that research is an intrinsically valuable activity distinguished residents who chose research as a career path from those who were undecided $(p=0.004)$. The belief that research is a means to better clinical practice also divided those who chose research from those who rejected it $(p=0.02)$.

CONCLUSION Our findings suggest that specific beliefs determine the level of research activity and career interest among residents. Novel strategies may be incorporated in training programmes to improve the interest and participation of residents in research, and to facilitate the development of academic clinicians.

Keywords: attitudes, barriers, clinician-scientist, practices

\section{INTRODUCTION}

Research activity is an integral part of residency training.(1) The Accreditation Council for Graduate Medical Education (ACGME) programme requirements for graduate medical education in internal medicine state that "intrinsic to the discipline are scientific knowledge, the scientific method of problem-solving, evidence-based decision-making, [and] a commitment to lifelong learning...".(2) Research promotes critical thinking, stimulates intellectual curiosity and develops essential lifelong-learning skills - traits that are required in the 21 st-century era of evidence-based medicine. ${ }^{(3-7)}$ Studies have shown that residents who received research training have a greater appreciation for evidence-based medicine ${ }^{(8)}$ and better clinical competence scores. ${ }^{(9)}$ Importantly, research training may encourage interest in pursuing a clinician-scientist career, a small but critical sector of the medical profession that is unfortunately seeing a decline in numbers. ${ }^{(10,11)}$ The career path of a clinician-scientist may be perceived to be demanding, as it combines clinical service and research commitments on top of mentoring and administrative responsibilities. In addition, individuals may feel disadvantaged in terms of career progression or fear being misconstrued by their peers as being inferior clinicians due to their involvement in research. ${ }^{(10)}$ Exploring factors that determine the career choices of residents may help to identify and nurture the development of potential clinician-scientists.
Early studies on internal medicine residency training programmes showed that research training during residency was appreciated by residents. ${ }^{(12,13)}$ However, the actual voluntary participation rate in research training remains low, presumably due to the difficulties faced by residents who have heavy clinical duties. Oft-cited barriers to performing research activity include a lack of the following: time; mentorship; faculty support; an organised research curriculum or network; knowledge and skills; incentives and rewards; research funding; and a personal interest in research. ${ }^{(3-5,14-16)}$

Over the past decade, Singapore has witnessed a dramatic transformation of traditional clinical institutions into academic medical centres. This transformation has been, in part, fuelled by the partnership formed among Duke University, National University of Singapore (NUS) and SingHealth institutions, ${ }^{(17-19)}$ and the recent establishment of the Lee Kong Chian School of Medicine by Imperial College London and Nanyang Technological University. These unique collaborations have brought together a predominantly clinical United Kingdom-based system with more academic-driven curriculums. As these cultural shifts are being implemented, it would be beneficial to survey the attitudes of trainee doctors with regard to research activity, as the information collected can be used to guide the establishment of a framework for graduate medical training programmes. Thus, the present study aimed to examine the participation rate of residents in research and their attitudes and perceived barriers toward research, by surveying junior

\footnotetext{
Department of Medical Oncology, National Cancer Centre Singapore, ${ }^{2}$ Department of Internal Medicine, ${ }^{3}$ Division of Medicine, Singapore General Hospital, ${ }^{4}$ Singapore Eye Research Institute, Singapore National Eye Centre, ${ }^{5}$ Duke-NUS Medical School, National University of Singapore, ${ }^{6}$ Department of Rheumatology and Immunology, ${ }^{7}$ Department of Respiratory and Critical Care Medicine, Singapore General Hospital, Singapore

Correspondence: Dr Ghee Chee Phua, Senior Consultant, Department of Respiratory and Critical Care Medicine, Singapore General Hospital, Outram Road, Singapore 169608. phua.ghee.chee@sgh.com.sg
} 
residents from an established ACGME-accredited internal medicine residency training programme in Singapore. The results from the survey should be especially relevant to traditional clinical hospitals that are evolving into university-linked academic medical centres.

\section{METHODS}

From October 2013 to November 2013, questionnaires were sent, either directly by hand or via email, to all residents ( $n=128)$ in an ACGME-accredited internal medicine training programme managed by SingHealth, the largest healthcare group in Singapore. The questionnaires were completed anonymously and submitted at designated collection points or electronically via a website. All data collected was kept confidential. This study was exempted from review by the local Institutional Review Board.

The questionnaire comprised three sections. The first section was on the residents' demographic and professional characteristics (e.g. age, gender, medical school of graduation, year of residency and postgraduate qualifications, if any). The second section was on the residents' level of participation in research during residency and their likely career choices after residency out of four given tracks - research, education, clinical services and administration. Residents were asked to indicate the likelihood of them choosing each of the four listed tracks, with each track presented on a fivepoint Likert scale ranging from 'definitely no' to 'definitely yes', with 'do not know yet' in the middle. The last section was on the residents' beliefs about research, their perceived barriers to doing research during residency, and their satisfaction with research training and opportunities during residency. The residents' beliefs about research were measured using a ten-item scale that was designed for this study. The scale was developed after a review of relevant literature and discussion with internal medicine residency programme faculty members. Satisfaction with research training and opportunities during residency was measured using a four-point Likert scale that ranged from 'very dissatisfied' to 'very satisfied', without a neutral category in the middle. Before the questionnaire was finalised, it was pilot-tested with a small group of ten resident representatives for ease of comprehension, relevance to their intended purpose and interpretation. Scholarly activities were defined, based on the ACGME guidelines, as: (a) the scholarship of discovery, as evidenced by peer-reviewed funding or publication in a peer-reviewed journal; (b) the scholarship of dissemination, as evidenced by review articles or chapters in textbooks; and/or (c) the scholarship of application, as evidenced by publication or presentation at local, regional, or national professional and scientific society meetings.

Descriptive analyses were performed on all collected data. Chi-square analyses were used to compare binarised categorical data across different domains of satisfaction with residency training. Exploratory factor analysis was performed to identify latent construct domains underlying the ten items on residents' beliefs about research. Cronbach's alpha was employed to estimate the internal consistency of the dimensions. Principal component analysis was used as the extraction method and an orthogonal rotation method (i.e. Varimax algorithm) was applied to compute factor loadings. Factor loadings above a threshold of 0.50 were used to indicate significant correlation between the item and construct. Multiple logistic regression analysis was performed to identify potential independent variables associated with research participation; the findings were expressed as odds ratios and $95 \%$ confidence intervals $(\mathrm{Cls})$. Multivariate multinomial regression analysis was employed to identify variables associated with the likelihood of choosing research as a career pathway; the findings were presented as relative risk ratios (RRRs) and 95\% Cls. Data was analysed using SPSS Statistics version 17.0 (SPSS Inc, Chicago, IL, USA). For all analyses, a two-sided $p$-value $<0.05$ was considered statistically significant.

\section{RESULTS}

Of the 128 surveys sent out, 82 were completed and returned, yielding an overall response rate of $64.1 \%$. The median age of the 82 respondents was 28 (range $24-33$ ) years. Respondents were in their first $(n=28)$, second $(n=26)$ and third $(n=27)$ years of training (one respondent did not indicate his/her number of years of training). There was higher representation from third-year residents $(27 / 35,77.1 \%)$ as compared to first-year $(28 / 51,54.9 \%)$ or secondyear $(26 / 42,61.9 \%)$ residents. The demographic and professional characteristics of the respondents are summarised in Table I.

Table I. Demographics of respondents $(n=82)$.

\begin{tabular}{|c|c|}
\hline Characteristic & No. (\%) \\
\hline Age* $^{*}(y r)$ & $28.3 \pm 2 . C$ \\
\hline \multicolumn{2}{|l|}{ Gender } \\
\hline Male & $41(50.0)$ \\
\hline Female & $41(50.0)$ \\
\hline \multicolumn{2}{|c|}{ Year of residency ${ }^{+}$} \\
\hline 1 st & $28(34.6)$ \\
\hline 2nd & $26(32.1)$ \\
\hline $3 r d$ & $27(33.3)$ \\
\hline \multicolumn{2}{|l|}{ Medical school ${ }^{+}$} \\
\hline NUS & $36(44.4)$ \\
\hline Duke-NUS & $11(13.6)$ \\
\hline Overseas & $34(42.0)$ \\
\hline \multicolumn{2}{|c|}{ Postgraduate qualification* } \\
\hline MRCP & $48(58.5)$ \\
\hline MSc & $9(11.0)$ \\
\hline $\mathrm{PhD}$ & $1(1.2)$ \\
\hline \multicolumn{2}{|c|}{ Duration of clinical practice prior to residency ${ }^{\S}(y r)$} \\
\hline$>4$ & $40(48.8)$ \\
\hline$>3$ & $15(18.3)$ \\
\hline$>2$ & $9(11.0)$ \\
\hline$>1$ & $11(13.4)$ \\
\hline $0-1$ & 7 (8.5) \\
\hline \multicolumn{2}{|c|}{ Currently doing research } \\
\hline Yes & $27(32.9)$ \\
\hline No & $55(67.1)$ \\
\hline
\end{tabular}

*Data presented as mean \pm standard deviation. + Total does not add up to 82 due to missing data. $¥$ Some respondents have $>1$ postgraduate qualification. §Most residents had clinical practice experience after graduation from medical school, prior to commencement of formal residency training. MRCP: Membership of the Royal Colleges of Physicians; MSc: Master of Science; NUS: National University of Singapore; PhD: Doctor of Philosophy 
Table II. Exploratory factor analysis of the residents' beliefs about research.

\begin{tabular}{|c|c|c|}
\hline Factor & $\begin{array}{l}\text { Valuing research as } \\
\text { a means to an end }\end{array}$ & $\begin{array}{l}\text { Valuing research as } \\
\text { an end itself }\end{array}$ \\
\hline Research is an asset to a fellowship/senior residency position application. & 0.719 & 0.281 \\
\hline Research is an essential component of an internal medicine residency. & 0.789 & 0.229 \\
\hline Research is an important component of clinical training. & 0.863 & 0.134 \\
\hline Research improves clinical proficiency and quality of patient care. & 0.538 & 0.419 \\
\hline Research develops essential skills for lifelong learning. & 0.262 & 0.785 \\
\hline Research develops critical thinking. & 0.206 & 0.783 \\
\hline Research allows the advancement of scientific/medical knowledge and education. & 0.227 & 0.738 \\
\hline Research facilitates training to be clinician investigators/scientists. & 0.238 & 0.735 \\
\hline Research satisfies intellectual curiosity. & 0.568 & 0.515 \\
\hline
\end{tabular}

Values are based on the responses of 79 residents, as 3 residents did not provide complete answers for this section. Principal component analysis was used as the extraction method and an orthogonal rotation method (i.e. Varimax algorithm) was applied to compute factor loadings.

At the time of the survey, 27 (32.9\%) of the respondents were involved in research activities. All except one of these 27 residents had projects in progress (the study did not explore why the one resident did not have a project in progress); 18 (66.7\%) reported spending at least $10 \%-50 \%$ of all their time (including personal time out of regular duty hours) on research activities, while the rest $(n=9)$ spent $<10 \%$ of their time on research. All of the residents who were involved in research activities had published in conference proceedings $(\mathrm{n}=16,59.3 \%)$ or journals $(\mathrm{n}=11$, $40.7 \%) ; 11(40.7 \%)$ had pending publications and 2 (7.4\%) had secured grant funding.

Only $33(40.2 \%)$ of the respondents indicated that they would likely or definitely choose the research track among the four career tracks listed, while $73(89.0 \%)$ chose the clinical services pathway and 50 (61.0\%) chose the education pathway. Administration was the only career track that fell behind research ( $\mathrm{n}=14,17.1 \%$ ). None of the respondents ruled out clinical services as a possible career choice, but 8 (9.8\%) did so for education, $20(24.4 \%)$ for research and 28 (34.1\%) for administration. It was interesting to note that there was a greater sense of uncertainty about a career in research than in education or clinical services; 34 (41.5\%) of the residents surveyed were unsure if they would choose a research pathway (i.e. they selected 'do not know yet'), compared to only 25 (30.5\%) for education and 9 (11.0\%) for clinical services. The uncertainty was slightly higher for administration ( $n=40,48.8 \%)$. The results of the survey suggest that, in terms of the residents' likely career choices after residency, the likelihood of choosing a career path in research is closer to the likelihood of a career path in administration than in education or clinical services.

Reliability analysis of the ten items intended to measure the residents' beliefs about research showed that one item, 'Research should be made compulsory', had low correlation with the other nine items. After this item was removed, Cronbach's alpha increased from 0.843 to 0.867 , indicating that the remaining nine items formed a more reliable scale. Exploratory factor analysis of the nine items yielded two distinct beliefs about research: (a) research is an intrinsically valuable activity; and (b) research is a means to better training and clinical care. Together, these two factors accounted for $62.5 \%$ of the total
Table III. Satisfaction with aspects of residency training among the residents $(n=81)$.

\begin{tabular}{|c|c|}
\hline Characteristic & No. (\%) \\
\hline Clinical education opportunities* & $78(96.3)$ \\
\hline Research education opportunities ${ }^{*,+}$ & $60(74.1)$ \\
\hline Opportunities to participate in research projects $s^{*,+}$ & $59(72.8)$ \\
\hline Residency training programme as a whole ${ }^{+}$ & 79 (97.5) \\
\hline
\end{tabular}

The satisfaction scores for research education opportunities and opportunities to participate in research projects were significantly lower than those for clinical education opportunities ( ${ }^{*}$ both $p=0.0005$ ); they were also lower than those for the residency training programme as a whole ( ${ }^{+}$both $\left.p=0.001\right)$.

variance among the nine items. The factor loadings of the items are presented in Table II.

Satisfaction scores for research training and opportunities during residency were about $20 \%$ lower than those for clinical education opportunities and overall satisfaction with residency training; these differences were statistically significant (both $\mathrm{p} \leq 0.001$ ). The lower satisfaction with research education did not have an appreciable impact on the residents' overall satisfaction with the residency training programme. This suggests that research education was evaluated separately and viewed as separate from the residency training programme (Table III).

The most frequently cited barrier to research was the lack of time $(85.0 \%)$, which was among the top three most significant barriers for the majority of residents $(71.3 \%)$. The two other most significant barriers were lack of personal interest (28.8\%) and lack of skill to perform statistical analyses (25.0\%). Overall, about $60 \%$ of the respondents cited the following reasons as barriers to research: lack of skill to perform statistical analyses; lack of research experience; and lack of training in research methodology (Fig. 1). Notably, however, $97.6 \%$ of the respondents indicated that they had some type of research exposure prior to their residency training. The research exposure could have been in the form of experience in extracting data from medical records $(72.0 \%)$, reviewing literature $(67.1 \%)$, interviewing patients $(63.4 \%)$, performing statistical analysis $(58.5 \%)$, writing research manuscripts (36.6\%), presenting at professional meetings (30.5\%), performing laboratory work $(29.3 \%)$, conducting in-depth interviews or focus groups (15.9\%), applying for grants (15.9\%) and/or conducting clinical trials (13.4\%). 


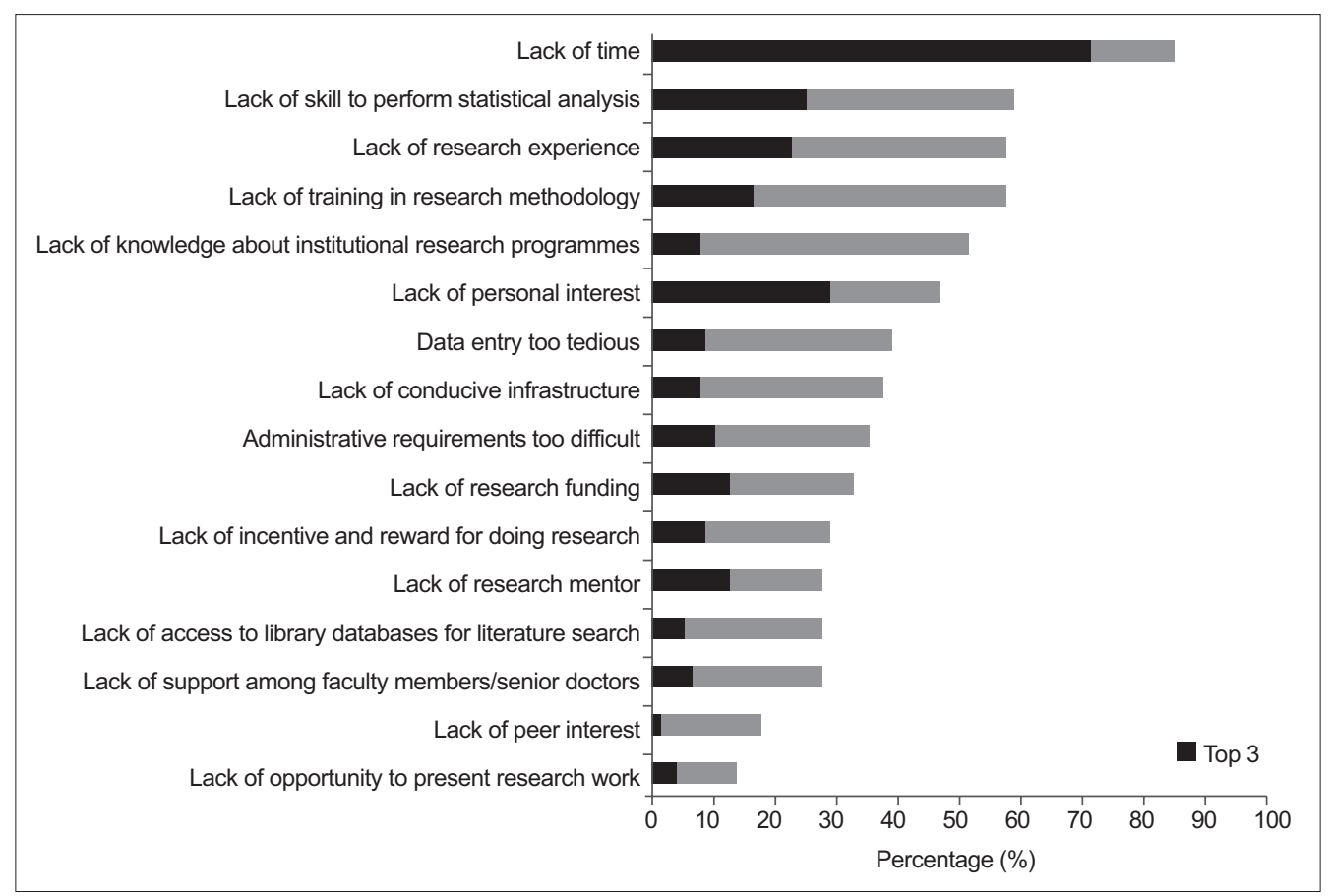

Fig. 1 Bar graph shows the barriers to performing research among the residents $(n=80)$, including barriers to starting or continuing with research during residency training. The top three most important barriers to each resident are cumulatively represented by the bars in black.

Contrary to conventional wisdom, bivariate analysis showed that none of the commonly cited barriers had a statistically significant association with the residents' actual participation in research during residency. The only variables that were found to matter were the possession of a postgraduate qualification and residents' beliefs about research (i.e. research is a means to an end or it is an end in itself). These three variables were entered into a multivariate logistic regression and the results are presented in Table IV. Residents with a postgraduate qualification were found to be nearly four times more likely to be active in research during residency than those without one. While the same pattern was observed for those who believed research to be an intrinsically valuable activity, the effect of this belief did not reach statistical significance $(p>0.05)$.

Bivariate analysis revealed that the following variables had a statistically significant association with the likelihood of choosing research as a career pathway: gender; medical school of graduation; active participation in research during residency; and beliefs about research. These variables were entered into a multivariate multinomial regression and the results are presented in Table V. Graduates from Duke-NUS Medical School and overseas universities were found to be far more likely to choose research as a career path after residency than their counterparts from local undergraduate medical schools. Notably, the belief that research is an intrinsically valuable activity distinguished residents who chose research from those who were undecided, and the belief that research is a means to better training and clinical care (i.e. it has extrinsic value) distinguished those who chose research from those who rejected it. Every one-point increase (on the fourpoint scale) in belief about the intrinsic value of research doubled the likelihood of choosing research as a career path, rather than being undecided about it (RRR 2.06, $p=0.004$ ). Likewise, a
Table IV. Factors associated with participation in research during residency.

\begin{tabular}{lcc}
\hline Factor & Odds ratio* $\mathbf{( 9 5 \% ~ C l )}$ & p-value \\
\hline $\begin{array}{l}\text { Possess a } \\
\text { postgraduate degree }\end{array}$ & $4.71(1.35-16.43)$ & 0.015 \\
$\begin{array}{l}\text { Value research as a } \\
\text { means to an end }\end{array}$ & $1.67(0.40-6.97)$ & 0.481 \\
$\begin{array}{l}\text { Value research as an } \\
\text { end in itself }\end{array}$ & $4.41(0.83-23.54)$ & 0.082 \\
\hline
\end{tabular}

*Obtained by multivariate logistic regression analysis. +Score range: 1-4. $\mathrm{Cl}$ : confidence interval

one-point increase in belief about the extrinsic value of research corresponded to a doubling of the likelihood of choosing research as a career path rather than rejecting it (RRR 2.04, $\mathrm{p}=0.02)$.

\section{DISCUSSION}

Consistent with earlier reports, ${ }^{(3,4,14-16)}$ the present study identified the lack of time as one of the most significant impediments to research activity during residency. However, although $85.0 \%$ of the respondents in our study agreed that lack of time was a barrier to research, about one-third were voluntarily involved in research activity during residency training. We also found that more than half of the residents who were active in research spent between $10 \%$ and $50 \%$ of their time on research-related activities. This is substantial, considering the fact that a large portion of time during residency training is typically used for clinical duties, and in improving clinical competency and knowledge in preparation for examinations. It is intriguing how and why this group of residents manage to engage in research despite an absence of protected time for research and the multitude of barriers listed. Given the barriers that need to be overcome in order to perform research, ${ }^{(20)}$ the underlying motivation to voluntarily do so must stem from an 
Table V. Relative risk ratios of choosing research as a career path after residency training, relative to rejecting the idea or being undecided about it.

\begin{tabular}{|c|c|c|c|c|c|c|}
\hline \multirow[t]{2}{*}{ Characteristic } & \multicolumn{3}{|c|}{$\begin{array}{l}\text { Choosing vs. rejecting } \\
\text { a research career }\end{array}$} & \multicolumn{3}{|c|}{$\begin{array}{l}\text { Choosing vs. undecided about a } \\
\text { research career }\end{array}$} \\
\hline & RRR & $95 \% \mathrm{Cl}$ & p-value & RRR & $95 \% \mathrm{Cl}$ & p-value \\
\hline Female gender & 3.80 & $0.73-19.88$ & 0.11 & 1.56 & $0.44-5.50$ & 0.49 \\
\hline \multicolumn{7}{|l|}{ Medical school } \\
\hline Duke-NUS \& overseas schools & 8.44 & $1.27-55.99$ & 0.03 & 11.61 & $2.35-57.39$ & 0.003 \\
\hline Active participation in research during residency & 6.18 & $0.80-47.54$ & 0.08 & 3.52 & $0.88-14.04$ & 0.07 \\
\hline \multicolumn{7}{|l|}{ Belief about research } \\
\hline It is an end in itself & 1.55 & $0.89-2.68$ & 0.12 & 2.06 & $1.27-3.36$ & 0.004 \\
\hline It is a means to an end & 2.04 & $1.12-3.72$ & 0.02 & 1.13 & $0.69-1.86$ & 0.62 \\
\hline
\end{tabular}

$\mathrm{Cl}$ : confidence interval; NUS: National University of Singapore; RRR: relative risk ratio

intrinsic attitude. The fact that the likelihood of participating in research increased fourfold with every one-point increase in the strength of belief in the intrinsic value of research, although not statistically significant, lends empirical support to this argument. Our results suggest that extrinsic incentives are not significantly associated with research participation. In Singapore, while research performance is often a prerequisite for securing clinical consultancy positions, it is not necessarily so for fellowship or senior residency positions. Furthermore, research work at the residency level is often performed on a voluntary basis, precluding any financial incentive.

Another factor that was found to be associated with active research participation in the present study was the completion of a postgraduate examination, which could have possibly freed up time for research activity. It has been demonstrated that the implementation of work-hour restrictions allowed residents time to develop academic interests and resulted in an increase in resident research publications. ${ }^{(21)}$ However, the research participation rate in our training programme was low, despite adherence to the restriction of 80 work-hours per week. While the reason for this is unclear, we also found that belief in the intrinsic value of research may have had a marked effect on research participation; hence, the lower-than-expected participation rate may be an indication of weak belief in the intrinsic value of research among the group of residents who were surveyed. Inconsistent findings on the effect of extrinsic incentives (e.g. offering protected time) to encourage research ${ }^{(3,7,22-24)}$ is further evidence of the need for studies that examine the beliefs of residents about research and the association of these beliefs with their inclination to actively participate in research.

A new finding from the present study is that differing beliefs about research are associated with variances in the likelihood of choosing research as a career path. This is an important discovery. Based on this finding, efforts to include research in residency training and clinical practice may influence the $24.4 \%$ of respondents who rejected it to consider research as a career choice. However, the effect of such efforts on the $41.5 \%$ who were undecided is likely to be small, as what set them apart from those who chose research was the strength of their belief in the intrinsic value of research. For this group of residents, creative methods that show the gratification involved in doing research may have a greater impact.
The results of the present study suggest that residents' participation in research and career choices may be influenced by specific beliefs. The reasons for their beliefs are unclear and while we did not directly investigate this in our study, we speculate that the current prescribed curriculum promoting research interest and behaviour may be a contributory factor. Given that lack of time was cited as a major barrier to research during residency, offering protected time may be a tenable approach. However, rather than providing unsupervised protected time for residents to explore research work, it may be more practical to grant protected time for a research syllabus instead.

In the SingHealth internal medicine residency programme, formal training in statistical analysis or research methodology is neither exhaustive nor individualised to specific needs. Therefore, the programme can be designed to provide structured training or technical support in research methodology, as well as offer opportunities for personal and mentored research experiences. This may be especially relevant in our local context, given that the majority of the residents surveyed reported that a lack of skill in statistical analysis, lack of research experience and lack of training in research methodology were barriers to participating in research activities during residency. The current curriculum needs development in order to appeal to different groups of residents with varying beliefs and interests, and should be individualised to overcome specific barriers.

In conclusion, by examining the different beliefs about research and the barriers to research, the present study has shed new light on strategies to improve residents' interests and participation in research. In addition to removing barriers, innovative methods to strengthen specific residents' beliefs may be considered to enhance their participation in research activity and to promote the development of academic clinicians.

\section{ACKNOWLEDGEMENTS}

The authors thank all the residents who participated in this study.

\section{REFERENCES}

1. Hayward RA, Taweel F. Data and the internal medicine houseofficer: alumni's views of the educational value of a residency program's research requirement. J Gen Intern Med 1993; 8:140-2.

2. Accreditation Council for Graduate Medical Education. Program Requirements for Graduate Medical Education in Internal Medicine 
[online]. Available at: http://www.acgme.org. Accessed January 14, 2015.

3. Alguire PC, Anderson WA, Albrecht RR, Poland GA. Resident research in internal medicine training programs. Ann Intern Med 1996; 124:321-8.

4. Rivera JA, Levine RB, Wright SM. Completing a scholarly project during residency training. Perspectives of residents who have been successful. J Gen Intern Med 2005; 20:366-9.

5. Hamann KL, Fancher TL, Saint S, Henderson MC. Clinical research during internal medicine residency: a practical guide. Am J Med 2006; 119:277-83.

6. Does research make for better doctors? Lancet 1993; 342:1063-4.

7. Potti A, Mariani P, Saeed M, Smego RA Jr. Residents as researchers: expectations, requirements, and productivity. Am J Med 2003; 115:510-14

8. Smith M. Research in residency: do research curricula impact postresidency practice? Fam Med 2005; 37:322-7.

9. Kohlwes RJ, Shunk RL, Avins A, et al. The PRIME curriculum. Clinical research training during residency. J Gen Intern Med 2006; 21:506-9.

10. Salto-Tellez M, Oh VM, Lee EH. How do we encourage clinician scientists in Singapore? Ann Acad Med Singapore 2007; 36:879-80.

11. Tooke J, Wass J. Nurturing tomorrow's clinician scientists. Lancet 2013; 381 Suppl 1:S1-2.

12. Kantor SM, Griner PF. Educational needs in general internal medicine as perceived by prior residents. J Med Educ 1981; 56(9 Pt 1):748-56.

13. Kern DC, Parrino TA, Korst DR. The lasting value of clinical skills. JAMA 1985; 254:70-6.

14. Gill S, Levin A, Djurdjev O, Yoshida EM. Obstacles to residents' conducting research and predictors of publication. Acad Med 2001; 76:477.
15. Levine RB, Hebert RS, Wright SM. Resident research and scholarly activity in internal medicine residency training programs. J Gen Intern Med 2005; 20:155-9.

16. Takahashi O, Ohde S, Jacobs JL, et al. Residents' experience of scholarly activities is associated with higher satisfaction with residency training. J Gen Intern Med 2009; 24:716-20.

17. Soo KC. Singapore's proposed graduate medical school--an expensive medical tutorial college or an opportunity for transforming Singapore medicine? Ann Acad Med Singapore 2005; 34:176C-181C.

18. Wong TY. How to bridge the "valley of death" between a research discovery and clinical application? Ann Acad Med Singapore 2014; 43:422-4.

19. Krishnan RR, Ng I. Academic medicine: vision to reality. Ann Acad Med Singapore $2013 ; 42: 2-4$.

20. Rothberg MB. Overcoming the obstacles to research during residency: what does it take? JAMA 2012; 308:2191-2.

21. Namdari S, Baldwin KD, Weinraub B, Mehta S. Changes in the number of resident publications after inception of the 80 -hour work week. Clin Orthop Relat Res 2010; 468:2278-83.

22. Kanna B, Deng C, Erickson SN, et al. The research rotation: competencybased structured and novel approach to research training of internal medicine residents. BMC Med Educ 2006; 6:52.

23. Chan RK, Lockyer J, Hutchison C. Block to succeed: the Canadian orthopedic resident research experience. Can J Surg 2009; 52:187-95.

24. Ruiz J, Wallace EL, Miller DP, et al. A comprehensive 3-year internal medicine residency research curriculum. Am J Med 2011; 124:469-73. 